\title{
Identify Medical Waste Management Status by Different Types of Dental Institutions
}

\author{
Mi-Ae Sung \\ Department of Dental Hygienics, Daegu Health College
}

Objectives: We aimed to examine if dental waste was managed adequately at different types of dental institutions in D City, Korea. Methods: The staff responsible for disinfection at 101 dental offices and clinics ( 6 dentistry departments of general hospitals, 12 dental hospitals, and 83 dental clinics) was interviewed.

Results: Solid suction pump waste was handled appropriately at 4 general hospital dentistry departments $(66.7 \%), 6$ dental hospitals $(50.0 \%)$, and 15 dental clinics (18.1\%). Solid spittoon waste was handled appropriately at 4 general hospital dentistry departments $(66.7 \%), 7$ dental hospitals (58.3\%), and 14 dental clinics (16.9\%). Developer and fixer were handled appropriately by a subcontractor at 2 general hospital dentistry departments (100.0\%), 5 dental hospitals (100.0\%), and 24 dental clinics (75.0\%). Impression materials were handled appropriately at 4 general hospital dentistry departments (66.7\%), 6 dental hospitals (50.0\%), and 11 dental clinics (13.3\%). The plastic covers of intra-oral radiography films were handled appropriately at 5 general hospital dentistry departments (100.0\%), 8 dental hospitals (72.7\%), and 22 dental clinics $(30.1 \%)$.

Conclusion: Korea must implement detailed and specialized guidelines for the disposal of solid and general medical waste at dental institutions. Moreover, waste disposal training should be provided annually and not only once every three years.

Copyright (C) 2021. Korean Academy of Preventive Dentistry. All rights reserved.

This is an Open Access article distributed under the terms of the Creative Commons Attribution Non-Commercial License (http://creativecommons.org/licenses/ by-nc/4.0) which permits unrestricted non-commercial use, distribution, and reproduction in any medium, provided the original work is properly cited. 